\title{
Psycho-Social Predictors of Childbirth Fear in Pregnant Women: An Australian Study
}

\author{
Jocelyn Toohill1, Jennifer Fenwick ${ }^{1,2}$, Jenny Gamble1, Debra K. Creedy' ${ }^{1}$, Anne Buist², \\ Elsa Lena Ryding 4 \\ ${ }^{1}$ Griffith Health Institute, School of Nursing \& Midwifery, Griffith University, Brisbane, Australia \\ ${ }^{2}$ Gold Coast University Hospital, Gold Coast, Australia \\ ${ }^{3}$ University of Melbourne, Melbourne, Australia \\ ${ }^{4}$ Karolinska Institute, Stockholm, Sweden \\ Email: j.toohill@griffith.edu.au
}

Received 29 April 2014; revised 25 May 2014; accepted 2 June 2014

Copyright (C) 2014 by authors and Scientific Research Publishing Inc.

This work is licensed under the Creative Commons Attribution International License (CC BY).

http://creativecommons.org/licenses/by/4.0/

(c) (i) Open Access

\section{Abstract}

Background: Around $20 \%$ of birthing women report high levels of childbirth fear. Fear potentially impacts women's emotional health, preparation for birth, and birth outcomes. Evidence suggests that personal and external factors contribute to childbirth fear, however results vary. Aim: To identify pyscho-social factors associated with childbirth fear and possible antenatal predictors of childbirth fear according to women's parity. Method: 1410 women in second trimester and attending one of three public hospitals in south-east Queensland were screened for childbirth fear using the Wijma Delivery Expectancy/Experience Questionnaire (W-DEQ). Other measures included the Edinburgh Depression Scale (EPDS), Decisional Conflict Scale (DCS) and items from the EuroQol (EQ-5D) targeting Anxiety/Depression and Pain/Discomfort. In addition items measuring a previous mental health condition, social support and knowledge were used. Preferred mode of birth was also collected. Psycho-social factors were analysed to determine associations with childbirth fear. Multivariate analysis was used to determine predictors of fear. Results: Thirty-one percent $(n=190 / 604)$ of nulliparous and $18 \%(n=143 / 782)$ of multiparous women reported high fear levels. Having a mental health history, desiring a caesarean section, reporting moderate to high pain during pregnancy, having a non-supportive partner and perceiving less childbirth knowledge than peers, were associated with childbirth fear. Standard multiple regression analyses by parity determined that depression, decisional conflict, low social support and less perceived knowledge predicted levels of childbirth fear. The model explained $32.4 \%$ of variance in childbirth fear for nulliparous and $\mathbf{2 9 . 4 \%}$ for multiparous women. Conclusion: Psychosocial factors are significantly associated with childbirth fear. The identification of predictive psychosocial factors for childbirth fear indicates the importance of observing, assessing, and developing support strategies for women. Such strategies are required to decrease anxiety and depression for women during pregnancy, promote normal birth, and build social support to improve women's feelings 
and positive expectations of birth.

Keywords

Childbirth Fear, Predictors, Pain, Decisional Conflict, Depression, Social Support

\section{Introduction}

Giving birth for most women is a normal, healthy life event. However not all women believe they are capable of experiencing or achieving normal birth, and of having a positive birth experience. There is emerging evidence that childbirth fear may contribute to a longer labour, increased use of pain medication and emergency caesarean section (CS) [1]-[4]. In addition to emergency CS, childbirth fear has been linked to request for elective CS which consequently contributes to overall increases in CS rates [5]-[11]. High levels of childbirth fear in pregnancy are thought to influence women's decisions about birth mode. Previously Saisto et al. [12] identified that in Sweden and the United Kingdom, between $7 \%$ and 22\% of requests for CS were due to childbirth fear.

Women's emotional health in pregnancy, particularly a history of anxiety and/or depression, has also been linked to childbirth fear [13]-[15]. Women with antenatal childbirth fear and depression have been found to be at increased risk of postnatal depression and post-traumatic stress following birth [16]. Recently Raisanen et al. [17] explored perinatal risks for developing postnatal depression in more than 500,000 Finnish women. Although a history of depression was highly related to postnatal depression, these authors also reported that women with childbirth fear and no history of depression were almost three times more likely to develop postnatal depression [17].

Previous work by our team identified that in a large sample of Australian pregnant women $(n=1410)$, around $25 \%$ of women had high childbirth fear [18]. Personal variables such as age, education and income were not found to be associated with fear. However in line with the findings of others, parity and previous mode of birth (instrumental or caesarean section) were significantly associated with childbirth fear [4] [7] [18]-[21].

In Scandinavian countries, where the majority of childbirth fear research originated, antenatal care for fearful women has been primarily focused on improving women's emotional preparation to minimise requests for CS [8] [22]. Although there is growing evidence that childbirth fear plays a part in the decisions that pregnant women make about mode of birth, there is scant work of this nature within the Australian context. Unlike personal demographic characteristics, many psycho-social factors are potentially modifiable and important to understand if we wish to reduce women's childbirth fear and increase their confidence for normal birth.

The aim of this current paper was to:

1) Identify pyscho-social factors associated with childbirth fear and possible antenatal predictors of childbirth fear; and

2) Determine differences in predictors for childbirth fear by women's parity.

\section{Method}

\subsection{Sample and Data Collection}

2311 women between 12 and 24 weeks of pregnancy were approached in the antenatal clinics of three hospitals in south-east Queensland, Australia. The sample is drawn from participants $(n=1410)$ who consented to participate in the BELIEF study [23]. Women were between 12 and 24 weeks pregnant, of any parity and any obstetric risk. Participants completed a questionnaire seeking demographic and obstetric details as well as levels of childbirth fear as measured by the Wijma Delivery Expectancy/Experience Questionnaire (W-DEQ) form A. Inclusion and exclusion criteria, sample characteristics and data collection procedures have been reported elsewhere [18] [23]. Women were asked questions pertaining to their previous mental health and preferred mode of birth. Other psycho-social variables were collected using validated tools including: 1) the Edinburgh Postnatal Depression Scale (EPDS) [24]; 2) the Decisional Conflict Scale (DCS) [25]; 3) two questions from the EuroQol (EQ-5D) [26] [27] were administered to assess pain/discomfort and anxiety/depression; and 4) several questions from Drummond and Rickwood's [28] Childbirth Knowledge Questionnaire (CKQ) and their Social Support/ 
Persuasions Scale (SSPS) were included to assess knowledge; and partner/general social support (see Box 1 for more detail on each measure). Recruitment occurred between April 2012 and June 2013. Ethical approval was obtained from the university and the three participating health services.

\subsection{Data Analysis}

Descriptive statistics were conducted on all variables and reported previously [18]. Total scores for all standardised measures were calculated. The reliability of each scale used in the study was calculated. Cronbach's alpha values for the WDEQ were 0.94, EPDS 0.86, and DCS 0.97. Global scores were calculated for social support (minimum 0 and maximum 20) and childbirth knowledge (minimum 0 and maximum 18).

Analyses were conducted for the whole sample and then by parity against the psycho-social variables hypothesised to impact high childbirth fear levels. Tests for parametric data were: independent T-test, Pearson's product-moment correlation coefficient and ANOVA; and for non-parametric data tests were: chi square, Spearmann's Rank Order Correlation, Kruskal-Wallis and Mann-Whitney U. Multivariate analysis was conducted to

\section{Box 1. Validated measures used in the study.}

The W-DEQ measures fear of childbirth by asking participants to rate their depth of feeling against 33 expectations and experiences before birth (version A) and after birth (version B) [51]. Questions are presented in positive and negative

W-DEQ formats on a six point Likert scale from 0 - 5 requiring reverse scoring of positively formulated questions. A score equal to or lower than 37 is considered low fear, a score between 38 and 65 equates to moderate fear and a score equal to or higher than 66 represents a high level of fear [20].

The EPDS is widely used in perinatal research and useful in screening for antenatal and postnatal depression [24] [52]. The scale is a simple self-report questionnaire with 10 items. Women were asked to select one of four possible responses to each question. Each item is scored from 0 - 3 and summed to produce a total score. The range of scores is from 0 - 30 with higher scores indicating more negative feelings. The EPDS has been endorsed as a screening tool in the antenatal and postnatal Australian maternity population [53]. EPDS scores of $>12$ in the antenatal or postnatal period have been recommended as an indicator of probable depression but not diagnostic of depression [53].

The DCS is a validated psychometric 16 item scale, which investigates concepts that can compromise or facilitate effective decision making (O’Connor, 2010). A score of 25 or lower (out of a possible score of 100) on the Decisional Conflict Scale (DCS) indicates an ability to make decisions (O’Connor, 2010). Scores $\geq 37.5$ are associated with decision delay or feeling unsure about implementing decisions. Participants identify on a 5 point Likert scale of $1=$ strongly disagree to $5=$ strongly

DCS agree their certainty or uncertainty about decisions when there are tradeoffs of outcomes in a health related decision. The DCS has relevance to this study because determining a mode of birth for women who have fear of childbirth or who have had a previous CS can create uncertainty where the "individual feels uninformed about the alternatives, risks and benefits; is unclear about their personal values; or feels unsupported in making a choice or feels pressured to choose a course of action" [25].

EQ-5D developed by the international EuroQol Group [26] [27] is a 6-item self-report measure of health across the 5 dimensions of mobility, self-care, usual activities, pain/discomfort, and anxiety/depression [54]. The scale has been

EuroQol validated in healthy and unwell persons and can be used as a stand-alone measure or in conjunction with other

(EQ-5D) psychometric instruments. To gain a baseline of women's health status on the day of entering the study one question pertaining to experiencing moderate or extreme pain and another on experiencing anxiety/depression were used from this scale.

Childbirth Knowledge Questionnaire is a list of 9-items that each assess knowledge of behavioural techniques which may assist during the labour and birth process, attendance at antenatal classes, vicarious experiences relating to viewing and reading about childbirth and perceived knowledge about childbirth. Although Drummond and Rickwood [28] reported fair internal consistency (Cronbach's alpha $=0.68$ ) analysis for the current study indicated that the items were not related and did not form a scale with psychometric properties. Furthermore, different response options were used for different items preventing the calculation of a reliability coefficient. Therefore a global score was calculated using $0=$ No, $1=$ Yes for dichotomised questions and for five item responses $0=$ None to 4 = A lot or extremely; was assigned for a total possible score of 18. A question pertaining to behavioural techniques was not included.

SSPS is a brief 5-item scale validated for Australian childbearing women [28]. The measure includes items that examine verbal support received from a partner and/or significant others specific to the woman's current pregnancy and upcoming birth. The tool uses a 5-point Likert scale ranging from "never" or "none" to "very often” or "a lot" with higher scores

SSPS indicating the woman has more social support. Internal consistency was reported using Cronbach's alpha and found to be 0.61 which is low [28]. Analysis for the current study indicated that the items were not related and did not form a scale with psychometric properties. A global score was calculated using $0=$ None or never to $4=$ A lot or very often, for a total possible score of 20 . 
determine predictors of fear.

\section{Results}

\subsection{Childbirth Fear}

The mean childbirth fear score was 49.5, SD = 22 (reported previously in Toohill [18]). Thirty-one percent ( $\mathrm{n}=$ 190/604) of primiparous women and $18 \%(n=143 / 782)$ of multiparous women had high fear levels (defined as a score of $\geq 66$ on the WDEQ-A). This was a statistically significant difference in fear scores for nulliparous (M $=55.05, \mathrm{SD} 20.7)$ and multiparous women ( $\mathrm{M}=45.18$, SD 21.9, $\mathrm{p}<0.001)$ (Refer Toohill [18]).

\subsection{Birth Preference}

The majority of participants indicated they would prefer a vaginal birth $(\mathrm{n}=1220,86.5 \%)$ with around twelve percent $(\mathrm{n}=168,11.9 \%)$ indicating a preference for a caesarean delivery. Twenty-two women (1.6\%) indicated they were unsure or declined to respond. Of women indicating a preference for CS most were already mothers (multiparous: $\mathrm{n}=131,78 \%$; nulliparous: $\mathrm{n}=37,22 \%$ ). Around eight out of every ten multiparous women preferring caesarean section in the current pregnancy had a history of CS in their last birth $(n=103,78 \%)$. Refer Table 1.

Thirty-two percent $(n=54)$ of the 168 women preferring a CS had high childbirth fear scores (range 66 to 115) (multiparous: $\mathrm{n}=37,22 \%$; nulliparous: $\mathrm{n}=17,10 \%$ ).

\subsection{Previous Mental Health Condition}

A mental health condition prior to pregnancy was acknowledged by $26 \%(n=366)$ of women (refer to Table 1$)$. Of these women, the most frequent mental health condition experienced was depression $(n=145,10.3 \%)$ followed by anxiety $(n=62,4.4 \%)$ and PTSD $(n=8,0.6 \%)$. Around ten percent of women experienced a combination of conditions $(n=154,10.9 \%)$, commonly depression and anxiety $(n=117,75.9 \%)$. Of all women preferring CS around one-third reported suffering a mental health condition $(n=62,37 \%)$.

\subsection{Anxiety and Discomfort}

Women completed two EQ5D questions [29] (describing anxiety/depression today and pain/discomfort today) to assess their wellbeing at baseline. Around one-fifth of women $(n=254,18 \%)$ indicated they were experiencing moderate or extreme levels of anxiety or depression, and one-third $(n=512,36.2 \%)$ reported moderate or extreme levels of pain. These symptoms occurred at similar frequency for nulliparous and multiparous women (Table 1).

\subsection{Social Support and Childbirth Knowledge}

Support from the father of the baby was acknowledged by $94.3 \%(n=1329)$ of women. Three-quarters of women $(n=1062,75.4 \%)$ reported having the same level or more detailed childbirth knowledge compared to other women. When comparing knowledge by parity, nulliparous women indicated less knowledge than multiparous women ( $n=291,47.8 \%$ vs. $n=48,6 \%)$ (refer Table 1$)$.

\subsection{Decisional Conflict}

A score of 25 or lower (out of a possible score of 100) on the Decisional Conflict Scale (DCS) indicates an ability to make decisions [25]. Scores of $\geq 37.5$ are associated with decision delay or feeling unsure about implementing decisions. The DCS scores of pregnant women indicated some difficulty in implementing decisions, and this was most specific to nulliparous women (Mean $=37.7, \mathrm{SD}=21.5$, range $=0$ to 100 vs. multiparous: mean $=23.7, \mathrm{SD}=22.3$, range $=0$ to 100 ).

\subsection{Possible Depression}

Around 8\% ( $=111)$ of participants scored $>12$ on the EPDS. There was a similar incidence for nulliparous (n 
Table 1. Baseline psycho-social characteristics.

\begin{tabular}{|c|c|c|c|}
\hline Characteristics & $\begin{array}{l}\text { Nulliparous Study } \\
\text { Sample n (\%) }\end{array}$ & $\begin{array}{l}\text { Multiparous Study } \\
\text { Sample n (\%) }\end{array}$ & Total Study Sample n (\%) \\
\hline \multicolumn{4}{|l|}{ Preferred birth mode } \\
\hline Vaginal birth & $564(92.6)$ & $656(81.9)$ & $1220(86.5)$ \\
\hline Caesarean section & $37(6.1)$ & $131(16.4)$ & $168(11.9)$ \\
\hline Missing/not stated & $8(1.3)$ & $14(1.7)$ & $22(1.6)$ \\
\hline W-DEQ mean (SD, range) & $55.05(20.7,4$ to 128$)$ & 45.18 (21.9, 0 to 115$)$ & $49.5(21.9,0$ to 128$) n=1386$ \\
\hline Missing & $5(0.8)$ & $19(2.3)$ & $24(1.7)$ \\
\hline Decisional conflict scale mean (SD, range) & $37.7(21.5,0$ to 100$)$ & $23.7(22.3,0$ to 100$)$ & 29.7 ( 23,0 to 100$)$ \\
\hline Missing & $15(2.5)$ & $15(1.9)$ & $30(2.1)$ \\
\hline EPDS mean (SD, range) & $5.4(4.7,0$ to 24$)$ & 4.9 (4.6, 0 to 24$)$ & $5.1(4.6,0$ to 24$)$ \\
\hline \multicolumn{4}{|l|}{ Mental health problem prior to pregnancy } \\
\hline Yes & $155(25.5)$ & $211(26.3)$ & $366(26.0)$ \\
\hline No & $454(74.5)$ & 590 (73.7) & $1044(74.0)$ \\
\hline \multicolumn{4}{|l|}{ Anxiety/depression today (EQ5D) } \\
\hline Yes & $111(18.2)$ & $143(17.9)$ & $254(18.0)$ \\
\hline No & 497 (81.6) & $656(81.9)$ & $1153(81.8)$ \\
\hline Missing & $1(0.2)$ & $2(0.2)$ & $3(0.2)$ \\
\hline \multicolumn{4}{|l|}{$\geq$ Moderate pain/discomfort today (EQ5D) } \\
\hline Yes & $240(39.4)$ & $272(34.0)$ & $512(36.2)$ \\
\hline No & $368(60.4)$ & $527(65.8)$ & $895(63.6)$ \\
\hline Missing & $1(0.2)$ & $2(0.2)$ & $3(0.2)$ \\
\hline \multicolumn{4}{|l|}{ Partner support } \\
\hline Yes & 572 (93.9) & 757 (94.5) & 1329 (94.3) \\
\hline No & $29(4.8)$ & $33(4.1)$ & $62(4.4)$ \\
\hline Missing & $8(1.3)$ & $11(1.4)$ & $19(1.3)$ \\
\hline \multicolumn{4}{|l|}{ Birth knowledge } \\
\hline$<$ Knowledge than others & $291(47.8)$ & $48(6.0)$ & $339(24.0)$ \\
\hline$\geq$ Knowledge than others & 310 (50.9) & 752 (93.9) & $1062(75.4)$ \\
\hline Missing & $8(1.3)$ & $1(0.1)$ & $9(0.6)$ \\
\hline
\end{tabular}

$=53,8.8 \%)$ and multiparous women $(n=58,7 \%)$. Just over half $(n=63,57 \%)$ of women with an EPDS score of $>12$ had high childbirth fear (WDEQ $\geq 66)$, with $38 \%(n=24)$ of this group indicating severe childbirth fear (WDEQ-A $\geq 85$ ).

\subsection{Factors Associated with Childbirth Fear}

Psycho-social variables of having a mental health history, feeling anxious or depressed, lacking partner support, experiencing moderate to severe pain in second trimester, desiring a CS for this birth, and low childbirth knowledge were statistically associated with higher childbirth fear scores $(p<0.001)$. Spearman's product-moment 
correlation coefficient revealed significant relationships between childbirth fear and decisional conflict (DCS) (p $<0.001$ ), and depressive symptom scores (EPDS) $(\mathrm{p}<0.001$ ) both with moderate effect [30]. See Table 2.

When analysed for differences by parity, psycho-social characteristics remained significantly associated with high levels of childbirth fear in women having a first and subsequent baby but with nulliparous women consistently maintaining higher fear levels to multiparous women. See Table 3.

\subsection{Predictors of Childbirth Fear}

Following the identification of statistically significant associations, standard multiple regression was used to

Table 2. Comparison of childbirth fear by psychosocial factors.

\begin{tabular}{|c|c|c|c|c|c|}
\hline Characteristics & WDEQ score (Md) & n (\%) & Statistic & $\mathrm{p}$-value & Effect \\
\hline Preferred birth mode & & 1365 (96.8) & \multirow{4}{*}{$z=-3.77$} & \multirow{4}{*}{$<0.001$} & \multirow{4}{*}{$r=-0.10$} \\
\hline Vaginal & 48 & $1213(86.0)$ & & & \\
\hline Caesarean & 57 & 152 (10.8) & & & \\
\hline Missing & & $45(3.2)$ & & & \\
\hline Hx mental health & & 1386 (98.3) & \multirow{4}{*}{$\mathrm{z}=-7.44$} & \multirow{4}{*}{$<0.001$} & \multirow{4}{*}{$r=-0.20$} \\
\hline Yes & 58 & $358(25.4)$ & & & \\
\hline No & 46 & 1028 (72.9) & & & \\
\hline Missing & & $24(1.7)$ & & & \\
\hline Anxiety/depression today (EQ5D) & & $1383(98.1)$ & \multirow{4}{*}{$z=-11.3$} & \multirow{4}{*}{$<0.001$} & \multirow{4}{*}{$\mathrm{r}=-0.30$} \\
\hline Yes & 65 & $247(17.5)$ & & & \\
\hline No & 46 & $1136(80.6)$ & & & \\
\hline Missing & & $27(1.9)$ & & & \\
\hline Pain/discomfort & & $1383(98.1)$ & \multirow{4}{*}{$\mathrm{z}=-5.07$} & \multirow{4}{*}{$<0.001$} & \multirow{4}{*}{$r=-0.14$} \\
\hline Mod/extreme & 54 & $503(35.7)$ & & & \\
\hline None/mild & 47 & 880 (62.4) & & & \\
\hline Missing & & $27(1.9)$ & & & \\
\hline Knowledge & & 1378 (97.7) & \multirow{4}{*}{$z=-9.25$} & \multirow{4}{*}{$<0.001$} & \multirow{4}{*}{$\mathrm{r}=-0.25$} \\
\hline$<$ Than others & 59 & 335 (23.7) & & & \\
\hline > Than others & 45 & $1043(74.0)$ & & & \\
\hline Missing & & $32(2.3)$ & & & \\
\hline Partner supportive & & 1368 (97.0) & \multirow{4}{*}{$z=-5.26$} & \multirow{4}{*}{$<0.001$} & \multirow{4}{*}{$r=-0.14$} \\
\hline Yes & 48 & 1307 (92.7) & & & \\
\hline No & 66 & $61(4.3)$ & & & \\
\hline Missing & & $42(3.0)$ & & & \\
\hline EPDS & & 1386 (98.3) & \multirow{2}{*}{ rho $=0.43^{* *}$} & \multirow[b]{2}{*}{$<0.001$} & \multirow[b]{2}{*}{ rho $=0.43++$} \\
\hline Missing & & $24(1.7)$ & & & \\
\hline DCS & & 1356 (96.2) & \multirow{2}{*}{ rho $=0.389^{* *}$} & \multirow{2}{*}{$<0.001$} & \multirow{2}{*}{ rho $=0.389++$} \\
\hline Missing & & $54(3.8)$ & & & \\
\hline
\end{tabular}

Effect size for Pearson and Spearman correlation moderate = ++ based on Cohen [30]. 
Table 3. Psycho-social associations to childbirth fear by parity.

\begin{tabular}{|c|c|c|c|c|c|}
\hline Characteristics & WDEQ score (Md) & n (\%) & Statistic & p-value & Effect \\
\hline Preferred birth mode—nullipara & & 596 (97.9) & $\mathrm{z}=-3.03$ & 0.002 & $r=-0.01$ \\
\hline Vaginal & 55 & $559(91.8)$ & & & \\
\hline CS & 65 & $37(6.1)$ & & & \\
\hline Missing & & $13(2.1)$ & & & \\
\hline Preferred birth mode—multipara & & 769 (96) & $z=-4.09$ & $<0.001$ & $\mathrm{r}=-0.15$ \\
\hline Vaginal & 42 & $654(81.6)$ & & & \\
\hline CS & 54 & $115(14.4)$ & & & \\
\hline Missing & & $32(4.0)$ & & & \\
\hline Hx mental health nullipara & & $604(99.2)$ & $\mathrm{z}=-5.61$ & $<0.001$ & $\mathrm{r}=-0.23$ \\
\hline Yes & 66 & $153(25.1)$ & & & \\
\hline No & 52 & $451(74.1)$ & & & \\
\hline Missing & & $5(0.8)$ & & & \\
\hline Hx mental health multipara & & $782(97.6)$ & $z=-5.61$ & $<0.001$ & $\mathrm{r}=-0.20$ \\
\hline Yes & 54 & $205(25.6)$ & & & \\
\hline No & 41 & $577(72.0)$ & & & \\
\hline Missing & & $19(2.4)$ & & & \\
\hline Anx/depression nullipara & & 603 (99) & $z=-7.85$ & $<0.001$ & $\mathrm{r}=-0.32$ \\
\hline Yes & 69 & $111(18.2)$ & & & \\
\hline No & 52 & $492(80.8)$ & & & \\
\hline Missing & & $6(1.0)$ & & & \\
\hline Anx/depression multipara & & $780(97.4)$ & $\mathrm{z}=-8.51$ & $<0.001$ & $\mathrm{r}=-0.30$ \\
\hline Yes & 60 & $136(17.0)$ & & & \\
\hline No & 41 & $644(80.4)$ & & & \\
\hline Missing & & $21(2.6)$ & & & \\
\hline Pain/discomfort nullipara & & $603(99.0)$ & $\mathrm{z}=-3.35$ & 0.001 & $\mathrm{r}=-0.14$ \\
\hline Mod/extreme & 59 & $239(39.2)$ & & & \\
\hline None/mild & 53 & $364(59.8)$ & & & \\
\hline Missing & & $6(1.0)$ & & & \\
\hline Pain/discomfort multipara & & $780(97.4)$ & $\mathrm{z}=-3.53$ & $<0.001$ & $\mathrm{r}=-0.126$ \\
\hline Mod/extreme & 49 & $264(33.0)$ & & & \\
\hline None/mild & 42 & $516(64.4)$ & & & \\
\hline Missing & & $21(2.6)$ & & & \\
\hline
\end{tabular}




\begin{tabular}{|c|c|c|c|c|c|}
\hline \multicolumn{6}{|l|}{ Continued } \\
\hline Knowledge nullipara & & $597(98.0)$ & $\mathrm{z}=-5.01$ & $<0.001$ & $\mathrm{r}=-0.204$ \\
\hline$<$ Than others & 60 & $290(47.6)$ & & & \\
\hline > Than others & 51 & $307(50.4)$ & & & \\
\hline Missing & & $12(2.0)$ & & & \\
\hline Knowledge multipara & & 781 (97.5) & $z=-3.4$ & 0.001 & $\mathrm{r}=-0.121$ \\
\hline$<$ Than others & 56 & $45(5.6)$ & & & \\
\hline$>$ Than others & 43 & 736 (91.9) & & & \\
\hline Missing & & $20(2.5)$ & & & \\
\hline Partner supportive nullipara & & 596 (97.9) & $z=-3.52$ & $<0.001$ & $\mathrm{r}=-0.14$ \\
\hline Yes & 55 & $567(93.1)$ & & & \\
\hline No & 72 & $29(4.8)$ & & & \\
\hline Missing & & $13(2.1)$ & & & \\
\hline Partner supportive multipara & & $772(96.4)$ & $z=-3.98$ & $<0.001$ & $\mathrm{r}=-0.14$ \\
\hline Yes & 43 & 740 (92.4) & & & \\
\hline No & 64 & $32(4.0)$ & & & \\
\hline Missing & & $29(3.6)$ & & & \\
\hline EPDS nullipara & & $604(99.2)$ & rho $=0.455^{* *}$ & $<0.001$ & rho $=0.455^{++}$ \\
\hline Missing & & $5(0.8)$ & & & \\
\hline EPDS multipara & & 782(97.6) & rho $=0.422^{* *}$ & $<0.001$ & rho $=0.422++$ \\
\hline Missing & & $19(2.3)$ & & & \\
\hline DCS nullipara & & $594(97.5)$ & rho $=0.312^{* *}$ & $<0.001$ & rho $=0.312++$ \\
\hline Missing & & $15(2.5)$ & & & \\
\hline DCS multipara & & 786 (98.1) & rho $=0.374^{* *}$ & $<0.001$ & rho $=0.374++$ \\
\hline Missing & & $15(1.9)$ & & & \\
\hline
\end{tabular}

Effect size for Pearson and Spearman correlation moderate $=++$ based on Cohen [30].

assess if EPDS, DCS, global scores for social support and knowledge and parity predicted levels of childbirth fear. The predictive model explained $32.4 \%$ of the variance in childbirth fear for nulliparous women and $29.4 \%$ in multiparous women.

A comparison of Beta values indicated that depressive symptoms (EPDS) (beta $=0.360, \mathrm{p}<0.001$ ) contributed most to childbirth fear in both nulliparous and multiparous women than DCS (beta $=0.201, p<0.001$ ), social support (beta $=-0.149, \mathrm{p}<0.001$ ) childbirth knowledge (beta $=-0.133, \mathrm{p}<0.001$ ) and parity (beta $=$ $-0.122, \mathrm{p}<0.001$ ) (refer Table 4).

\section{Discussion}

A range of psychosocial variables contributed to childbirth fear. Possible depression, decisional conflict, lower levels of childbirth knowledge and lack of social support were predictors for childbirth fear in women. A significant strength of this work is the large representative nature of the sample that was inclusive of parity and obstetric risk (for example multiple pregnancy). However limitations such as recruiting women from the public sector only, and excluding women requiring an interpreter must be taken into consideration when interpreting the results. 
Table 4. Predictors for childbirth fear.

\begin{tabular}{ccccc}
\hline Parity & EPDS & DCS & Birth Knowledge & Social Support \\
\hline Nulliparous & $0.368^{* *}$ & $0.133^{*}$ & $-0.190^{* *}$ & $-0.179^{* *}$ \\
Multiparous & $0.373^{* *}$ & $0.230^{* *}$ & $-0.106^{*}$ & $-0.136^{* *}$ \\
\hline
\end{tabular}

EPDS—Edinburgh Postnatal Depression Scale; DCS—Decisional Conflict Scale; Birth Knowledge and Social Support—are global scores adapted from Drummond \& Rickwood [28]; Significance ${ }^{*}=0.001 ;^{* *}<0.0005$.

Our finding that women suffering anxiety or depression were more fearful is consistent with the work of others [9] [13] [31] [32]. While anxiety is reportedly more common than depression and higher in the first and third trimesters of pregnancy [33]-[35], depression alone has been associated with risk for childbirth fear [15]. In line with previous research, we also found depression symptoms (as measured by the EPDS) were a significant predictor for childbirth fear. Likewise Danish and Norwegian researchers found that the presence of anxiety and/or depression increased the risk for childbirth fear. However in their large sample size studies $(\mathrm{n}=30,480$ and $\mathrm{n}=$ 1642) the majority of fearful women were neither anxious nor depressed [14] [15]. Symptoms of depression may contribute to women having a negative view of their personal capabilities, and of seeing the world as a safe and predictable place. These views may manifest in feelings of fear and uncertainty about childbirth.

A surprising result was the high-level of pain and/or discomfort reported by women. While minor discomforts are common across pregnancy [36] [37], around 36\% of all women (39\% in nulliparous) in the current study reported experiencing moderate or extreme levels of pain during pregnancy. The experience of moderate or extreme pain and/or discomfort was associated with childbirth fear. This finding is consistent with previous research that reported women with childbirth fear complained more often of physical ailments; and experienced more severe pain in third trimester as determined by a cold pressor test [31] [38]. More recently Nordeng et al., [39] sought to determine the level of medication use in women with childbirth fear but did not find a relationship. While there is limited research on fear levels and antenatal discomfort; there is a link between antenatal fatigue and childbirth fear [19]. Somatic anxiety and muscle tension have also been associated with fear levels [40]. Arguably significant discomfort may be linked to fatigue levels and/or lower levels of confidence contributing to anxiety, tension and stress, and warrants further investigation.

While the majority of women in our study reported feeling well supported by their partners those who reported low support were more fearful. W-DEQ scores were on average 20 points higher in women who did not have partner support regardless of parity. These findings are consistent with previous research [9] [31]; and highlight the importance of maternity health care professionals exploring pregnant women's level of partner support. In contrast, Haines et al. [41] found no difference in levels of fear for women with or without partner support in a rural community. While fear measures varied across studies it may be that rural townships offer a greater sense of community that compensates for diminished direct partner support.

Again in line with findings of others, a lack of general social support was found to predict childbirth fear [14]. Social support is a buffer to stressful situations [42] and without emotional and social support women have a greater likelihood of adverse pregnancy outcomes including preterm birth and perinatal depression [43] [44]. Additionally, depression was found to be a risk factor for fear in this study. Women reporting childbirth fear may experience a vicious cycle whereby lack of social support contributes to depressive symptoms, and these symptoms diminish their ability to source and maintain social support.

A high level of decisional conflict, especially in first time mothers was common and associated with childbirth fear. A link between fear and decision-making has not been made previously. Indecision may be part of the same vicious cycle of events described above. While measuring decisional conflict has not been commonly undertaken, our findings are consistent with another study comparing Australian and Swedish women's birth attitudes and beliefs [45]. In that study one-third of women in both countries were unable to determine their preference around birth options, with Australian women more uncertain than Swedish women [45]. Despite the majority of women preferring normal birth, women with childbirth fear and depression may acquiesce to suggestions for a caesarean delivery. While higher decisional conflict in nulliparous women may be compounded by the unknown experience of birth, decisional conflict also contributed to childbirth fear in multiparous women, possibly due to conflict of having experienced a previous difficult birth.

Women's knowledge and/or cultural understanding of childbirth is also likely to play a significant role in how 
women approach birth. In our study multiparous women had higher levels of birth knowledge compared to nulliparous women, which is consistent with the work of others [28] [46]. Women who felt less informed had a higher propensity for childbirth fear. It could be that lack of knowledge contributed to a perceived lack of control and fear. Without information, women are disadvantaged in their decision-making and birth planning. Certainly there is evidence that where women are involved in decisions and birth planning they feel more in control [47] [48].

The identification of predictive factors for childbirth fear indicates the importance of assessing women and developing support strategies to ameliorate childbirth fear. Improving social support may reduce depressive symptoms perceptions of pain/discomfort and decisional conflict. Identifying effective and acceptable psychosocial interventions for pregnant women is critical to short and long-term maternal and infant health. Strategies are required to improve women's feelings and expectations of birth. These need to include developing women's knowledge to assist confidence with childbirth decisions, ensuring mechanisms are in place to monitor and treat anxiety and depression, and offering avenues for women during pregnancy to build social supports. Currently a randomised controlled trial is underway to test the efficacy of a midwife-led psycho-education intervention to address these issues with fearful pregnant women [23].

Support for this approach is evident in the research of those working with vulnerable and disadvantaged women whereby women receiving antenatal group care or continuity of midwifery care within social models have improved emotional health as well as birth outcomes [44] [49] [50].

\section{Conclusion}

Pregnant women with higher levels of childbirth fear report worse emotional, psychological and physical health. Psychosocial factors undoubtedly play a large part in how women having a first or subsequent baby feel about their upcoming birth. The results of this study support the recommendation that competent assessment of women with childbirth fear should occur to enable supportive strategies to be put in place, and that maternity providers should be skilled in listening and validating each woman's individual needs to alleviate women's negative feelings.

\section{Acknowledgements}

The BELIEF study was funded by NHMRC (grant ID APP1025099).

\section{References}

[1] Adams, S., Eberhard-Gran, M. and Eskild, A. (2012) Fear of Childbirth and Duration of Labour: A Study of 2206 Women with Intended Vaginal Delivery. BJOG, 119, 1238-1246. http://dx.doi.org/10.1111/j.1471-0528.2012.03433.x

[2] Fenwick, J., Gamble, J., Nathan, E., Bayes, S. and Hauck, Y. (2009) Pre- and Postpartum Levels of Childbirth Fear and the Relationship to Birth Outcomes in a Cohort of Australian Women. Journal of Clinical Nursing, 18, 667-677. http://dx.doi.org/10.1111/j.1365-2702.2008.02568.x

[3] Ryding, E., Lukasse, M. and Schei, B. (2012) Fear of Childbirth—Does It Affect Mode of Delivery. The BIDENS Study-Results from Six Countries. Acta Obstetricia et Gynecologica Scandinavica, 91, 38.

[4] Ryding, E., Wijma, B., Wijma, K. and Rydhstrom, H. (1998) Fear of Childbirth during Pregnancy May Increase the Risk of Emergency Cesarean Section. Acta Obstetricia et Gynecologica Scandinavica, 77, 542-547. http://dx.doi.org/10.1080/j.1600-0412.1998.770512.x

[5] Sydsjo, G., Sydsjo, A., Gunnervik, C., Bladh, M. and Josefsson, A. (2012) Obstetric Outcome for Women Who Received Individualized Treatment for Fear of Childbirth during Pregnancy. Acta Obstetricia et Gynecologica Scandinavica, 91, 44-49. http://dx.doi.org/10.1111/j.1600-0412.2011.01242.x

[6] Nerum, H., Halvorsen, L., Sorlie, T. and Oian, P. (2006) Maternal Request for Cesarean Section Due to Fear of Birth: Can It Be Changed through Crisis-Oriented Counseling? Birth, 33, 221-228. http://dx.doi.org/10.1111/j.1523-536X.2006.00107.x

[7] Nieminen, K., Stephansson, O. and Ryding, E.L. (2009) Women’s Fear of Childbirth and Preference for Cesarean Section-A Cross-Sectional Study at Various Stages of Pregnancy in Sweden. Acta Obstetricia et Gynecologica Scandinavica, 88, 807-813. http://dx.doi.org/10.1080/00016340902998436

[8] Sjogren, B. (1998) Fear of Childbirth and Psychosomatic Support. Acta Obstetricia et Gynecologica Scandinavica, 77, 819-825. http://dx.doi.org/10.1080/j.1600-0412.1998.770807.x 
[9] Waldenstrom, U., Hildingsson, I. and Ryding, E. (2006) Antenatal Fear of Childbirth and Its Association with Subsequent Caesarean Section and Experience of Childbirth. BJOG, 113, 638-646. http://dx.doi.org/10.1111/j.1471-0528.2006.00950.x

[10] Wiklund, I., Edman, G., Ryding, E. and Andolfa, E. (2008) Expectation and Experiences of Childbirth in Primiparae with Caesarean Section. BJOG, 115, 324-331. http://dx.doi.org/10.1111/j.1471-0528.2007.01564.x

[11] Wax, J., Cartin, A., Pinette, M. and Blackstone, J. (2004) Patient Choice Cesarean: An Evidence-Based Review. Obstetrical \& Gynecological Survey, 59, 601-616. http://dx.doi.org/10.1097/01.OGX.0000133942.76239.57

[12] Saisto, T., Toivanen, R., Salmela-Aro, K. and Halmesmaki, E. (2006) Therapeutic Group Psychoeducation and Relaxation in Treating Fear of Childbirth. Acta Obstetricia et Gynecologica Scandinavica, 85, 1315-1319. http://dx.doi.org/10.1080/00016340600756920

[13] Rouhe, H., Salmela-Aro, K., Gissler, M., Halmesmaki, E. and Saisto, T. (2011) Mental Health Problems Common in Women with Fear of Childbirth. BJOG, 118, 1104-1111. http://dx.doi.org/10.1111/j.1471-0528.2011.02967.x

[14] Laursen, M., Hedegaard, M. and Johansen, C. (2008) Fear of Childbirth: Predictors and Temporal Changes among Nulliparous Women in the Danish National Birth Cohort. BJOG, 115, 354-360. http://dx.doi.org/10.1111/j.1471-0528.2007.01583.x

[15] Storksen, H., Eberhrd-Gran, M., Garthus-Niegel, S. and Eskild, A. (2012) Fear of Childbirth; The Relation to Anxiety and Depression. Acta Obstetricia et Gynecologica Scandinavica, 91, 237-242. http://dx.doi.org/10.1111/j.1600-0412.2011.01323.x

[16] Söderquist, J., Wijma, B., Thorbert, G. and Wijma, K. (2009) Risk Factors in Pregnancy for Post-Traumatic Stress and Depression after Childbirth. BJOG: An International Journal of Obstetrics \& Gynaecology, 116, 672-680. http://dx.doi.org/10.1111/j.1471-0528.2008.02083.x

[17] Raisanen, S., Lehto, S., Nielsen, H., Gissler, M., Kramer, M., et al. (2013) Fear of Childbirth Predicts Postpartum Depression: A Population-Based Analysis of 511422 Singleton Births in Finland. BMJ Open, 3, e004047. http://dx.doi.org/10.1136/bmjopen-2013-004047

[18] Toohill, J., Fenwick, J., Gamble, J. and Creedy, D.K. (2014) Prevalence of Childbirth Fear in an Australian Sample of Pregnant Women (in Press).

[19] Hall, W., Hauck, Y., Carty, E., Hutton, E., Fenwick, J., et al. (2009) Childbirth Fear, Anxiety, Fatigue, and Sleep Deprivation in Pregnant Women. Journal of Obstetric, Gynecologic, \& Neonatal Nursing, 38, 567-576. http://dx.doi.org/10.1111/j.1552-6909.2009.01054.x

[20] Rouhe, H., Salmela-Aro, K., Halmesmäki, E. and Saisto, T. (2009) Fear of Childbirth According to Parity, Gestational Age, and Obstetric History. BJOG: An International Journal of Obstetrics \& Gynaecology, 116, 67-73. http://dx.doi.org/10.1111/j.1471-0528.2008.02002.x

[21] Zar, M., Wijma, K. and Wijma, B. (2001) Pre- and Postpartum Fear of Childbirth in Nulliparous and Parous Women. Scandinavian Journal of Behaviour Therapy, 30, 75-84. http://dx.doi.org/10.1080/02845710121310

[22] Ryding, E., Persson, A., Onell, C. and Kvist, L. (2003) An Evaluation of Midwives' Counseling of Pregnant Women in Fear of Childbirth. Acta Obstetricia et Gynecologica Scandinavica, 82, 10-17. http://dx.doi.org/10.1034/j.1600-0412.2003.820102.x

[23] Fenwick, J., Gamble, J., Creedy, D., Buist, A., Turkstra, E., et al. (2013) Study Protocol for Reducing Childbirth Fear: A Midwife-Led Psycho-Education Intervention. BMC Pregnancy and Childbirth, 13, Published Online.

[24] Cox, J., Holden, J. and Sagousky, R. (1987) Detection of Postnatal Depression Development of the 10 Item Edinburgh Depression Scale. BMJ, 150, 782-786.

[25] O’Connor, A. (2010) User Manual-Decisional Conflict Scale (16 Item Statement Format) [Document on the Internet]. Ottawa Hospital Research Institute, Ottawa. http://decisionaid.ohri.ca/docs/develop/User Manuals/UM Decisional Conflict.pdf.

[26] Brooks, R. (1996) EuroQol: The Current State of Play. Health Policy, 37, 53-72. http://dx.doi.org/10.1016/0168-8510(96)00822-6

[27] The EuroQol Group (1990) EuroQol: A New Facility for the Measurement of Health-Related Quality of Life. Health Policy, 16, 199-208. http://dx.doi.org/10.1016/0168-8510(90)90421-9

[28] Drummond, J. and Rickwood, D. (1997) Childbirth Confidence: Validating the Childbirth Self-Efficacy Inventory (CBSEI) in an Australian Sample. Journal of Advanced Nursing, 26, 613-622. http://dx.doi.org/10.1046/j.1365-2648.1997.t01-24-00999.x

[29] EuroQuol Group (2009) EQ5D User Guide. Version 2. http://www.euroquol.org

[30] Cohen, J. (1988) Statistical Power Analysis for the Behavioural Sciences. 2nd Edition, Erlbaum Associates, Hillsdale.

[31] Saisto, T., Salmela-Aro, K., Nurmi, J. and Halmesmäki, E. (2001) Psychosocial Characteristics of Women and Their 
Partners Fearing Vaginal Childbirth. BJOG: An International Journal of Obstetrics \& Gynaecology, 108, $492-498$. http://dx.doi.org/10.1111/j.1471-0528.2001.00122.x

[32] Zar, M., Wijma, K. and Wijma, B. (2002) Relations between Anxiety Disorders and Fear of Childbirth during Late Pregnancy. Clinical Psychology \& Psychotherapy, 9, 122-130. http://dx.doi.org/10.1002/cpp.305

[33] Atwood, A. (2013) Antenatal Anxiety: Origins, Effects, and Interventions. International Journal of Childbirth Education, 28, 54-60.

[34] Brockington, I., Macdonald, E. and Wainscott, G. (2006) Anxiety, Obsessions and Morbid Preoccupations in Pregnancy. Archives of Women's Mental Health, 9, 253-263. http://dx.doi.org/10.1007/s00737-006-0134-z

[35] Lee, A., Lam, S., Lau, S.M., Chong, C., Chui, H., et al. (2007) Prevalence, Course, and Risk Factors for Antenatal Anxiety and Depression. Obstetrics \& Gynecology, 110, 1102-1112. http://dx.doi.org/10.1097/01.AOG.0000287065.59491.70

[36] Rofé, Y., Littner, M. and Lewin, I. (1993) Emotional Experiences during the Three Trimesters of Pregnancy. Journal of Clinical Psychology, 49, 3-12. http://dx.doi.org/10.1002/1097-4679(199301)49:1<3::AID-JCLP2270490102>3.0.CO;2-A

[37] Shinkawa, H., Shimada, M., Hirokane, K., Hayase, M. and Inui, T. (2012) Development of a Scale for Pregnancy-Related Discomforts. Journal of Obstetrics and Gynaecology Research, 38, 316-323. http://dx.doi.org/10.1111/j.1447-0756.2011.01676.X

[38] Saisto, T., Kaaja, R., Ylikorkala, O. and Halmesmäki, E. (2001) Reduced Pain Tolerance during and after Pregnancy in Women Suffering from Fear of Labor. Pain, 93, 123-127. http://dx.doi.org/10.1016/S0304-3959(01)00302-5

[39] Nordeng, H., Hansen, C., Garthus-Niegel, S. and Eberhard-Gran, M. (2012) Fear of Childbirth, Mental Health, and Medication Use during Pregnancy. Archives of Women's Mental Health, 15, 203-209. http://dx.doi.org/10.1007/s00737-012-0278-y

[40] Ryding, E., Wirfelt, E., Wängborg, I., Sjögren, B., Edman, G., et al. (2007) Personality and Fear of Childbirth. Acta Obstetricia et Gynecologica Scandinavica, 68, 814-820. http://dx.doi.org/10.1080/00016340701415079

[41] Haines, H., Pallant, J., Karlström, A. and Hildingsson, I. (2011) Cross-Cultural Comparison of Levels of ChildbirthRelated Fear in an Australian and Swedish Sample. Midwifery, 27, 560-567. http://dx.doi.org/10.1016/j.midw.2010.05.004

[42] Turner, R.J., Grindstaff, C. and Phillips, N. (1990) Social Support and Outcome in Teenage Pregnancy. Journal of Health and Social Behavior, 31, 43-57. http://dx.doi.org/10.2307/2137044

[43] Collins, N., Dunkel-Schetter, C., Lobel, M. and Scrimshaw, S. (1993) Social Support in Pregnancy: Psychosocial Correlates of Birth Outcomes and Postpartum Depression. Journal of Personality and Social Psychology, 65, 1243-1258. http://dx.doi.org/10.1037/0022-3514.65.6.1243

[44] Rising, S. (1998) Centering Pregnancy: An Interdisciplinary Model of Empowerment. Journal of Nurse-Midwifery, 43, 46-54. http://dx.doi.org/10.1016/S0091-2182(97)00117-1

[45] Haines, H., Rubertsson, C., Pallant, J. and Hildingsson, I. (2012) Womens’ Attitudes and Beliefs of Childbirth and Association with Birth Preference: A Comparison of a Swedish and an Australian Sample in Mid-Pregnancy. Midwifery, 28, e850-e856. http://dx.doi.org/10.1016/j.midw.2011.09.011

[46] Lowe, N. (1993) Maternal Confidence for Labor: Development of the Childbirth Self-Efficacy Inventory. Research in Nursing \& Health, 16, 141-149. http://dx.doi.org/10.1002/nur.4770160209

[47] Helk, A., Spilling, H. and Smeby, N. (2008) Psychosocial Support by Midwives of Women with a Fear of Childbirth: A Study of 80 Women. Nordic Journal of Nursing Research \& Clinical Studies, 28, 47-49.

[48] Lothian, J.A. (2008) Choice, Autonomy, and Childbirth Education. The Journal of Perinatal Education, 17, 35-38. http://dx.doi.org/10.1624/105812408X266278

[49] McCourt, C. and Stevens, T. (2009) Relationship and Reciprocity in Caseload Midwifery. In: Hunter, B. and Deery, R., Eds., Emotions in Midwifery and Reproduction, Palgrave Macmillan, New York.

[50] Menke, J., Fenwick, J., Gamble, J., Brittain, H. and Creedy, D. (2014) Midwifery Group Practice for Socially Disadvantaged and Vulnerable Women: Midwives Perceptions of Organizational Structures and Processes Influencing Care. Midwifery. http://dx.doi.org/10.1016/j.midw.2013.12.015

[51] Wijma, K., Wijma, B. and Zar, M. (1998) Psychometric Aspects of the W-DEQ; A New Questionnaire for the Measurement of Fear of Childbirth. Journal of Psychosomatic Obstetrics \& Gynecology, 19, 84-97. http://dx.doi.org/10.3109/01674829809048501

[52] Murray, D. and Cox, J. (1990) Screening for Depression during Pregnancy with the Edinburgh Depression Scale (EPDS). Special Issue: Psychiatric Disorders Associated with Childbearing. Journal of Reproductive and Infant Psychology, 8, 99-107. http://dx.doi.org/10.1080/02646839008403615 
[53] Beyondblue (2011) Clinical Practice Guidelines for Depression and Related Disorders-Anxiety, Bipolar Disorder and Puerperal Psychosis-In the Perinatal Period. A Guideline for Primary Care Health Professionals. The National Depression Initiative, Melbourne.

https://www.bspg.com.au/dam/bsg/product?client=BEYONDBLUE\&prodid=BL/0891\&type=file.

[54] Williams, A. (2005) The EuroQol Instrument. In: Kind, P., Brooks, R. and Rabin, R., Eds., EQ-5D Concepts and Methods: A Developmental History, Springer, Dordrecht, 1-17. http://dx.doi.org/10.1007/1-4020-3712-0_1 